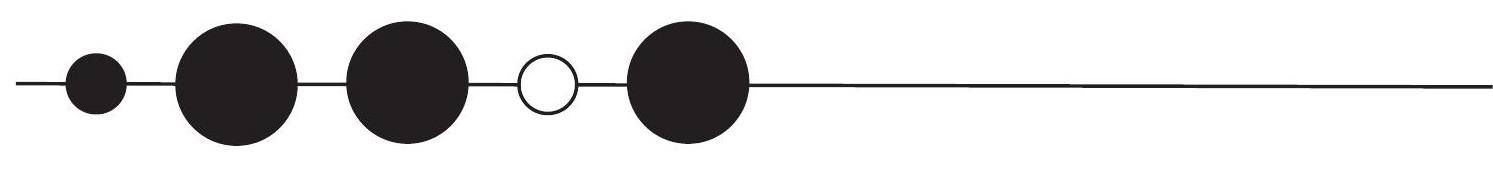




\section{FOLK UTEN LAND}

Fordrivelse, forfølgelse og okkupasjon. Det er erfaringer flere folkegrupper i Midtøsten og Nord-Afrika har måttet leve med innenfor dagens statsgrenser. For dem er frihet $\mathrm{i}$ en egen stat fortsatt en fjern drøm. Kurderne er splittet mellom flere stater, palestinerne og sahrawiene er fordrevet eller okkupert, mens berberne opplever undertrykkelse og diskriminering. Denne bildereportasjen viser noen glimt fra kurdere i Iran og Irak, palestinere i Libanon og Palestina, og berbere og sahrawier i Algerie. Alle bilder: ARE HOVDENAK 


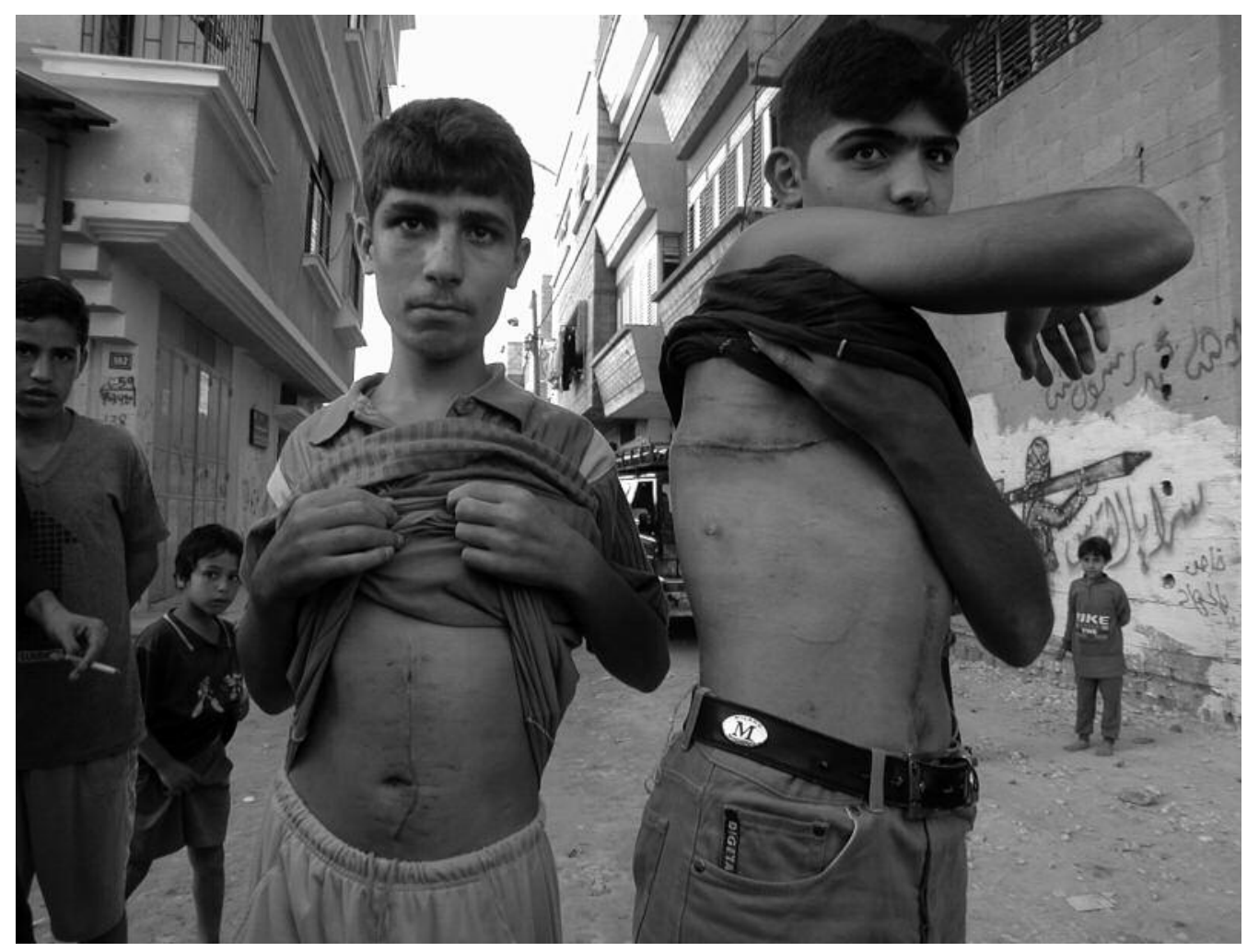

Gaza, november 2002. To gutter som overlevde et rakettangrep fra et israelsk helikopter, viser fram ferske arr etter operasjoner. 


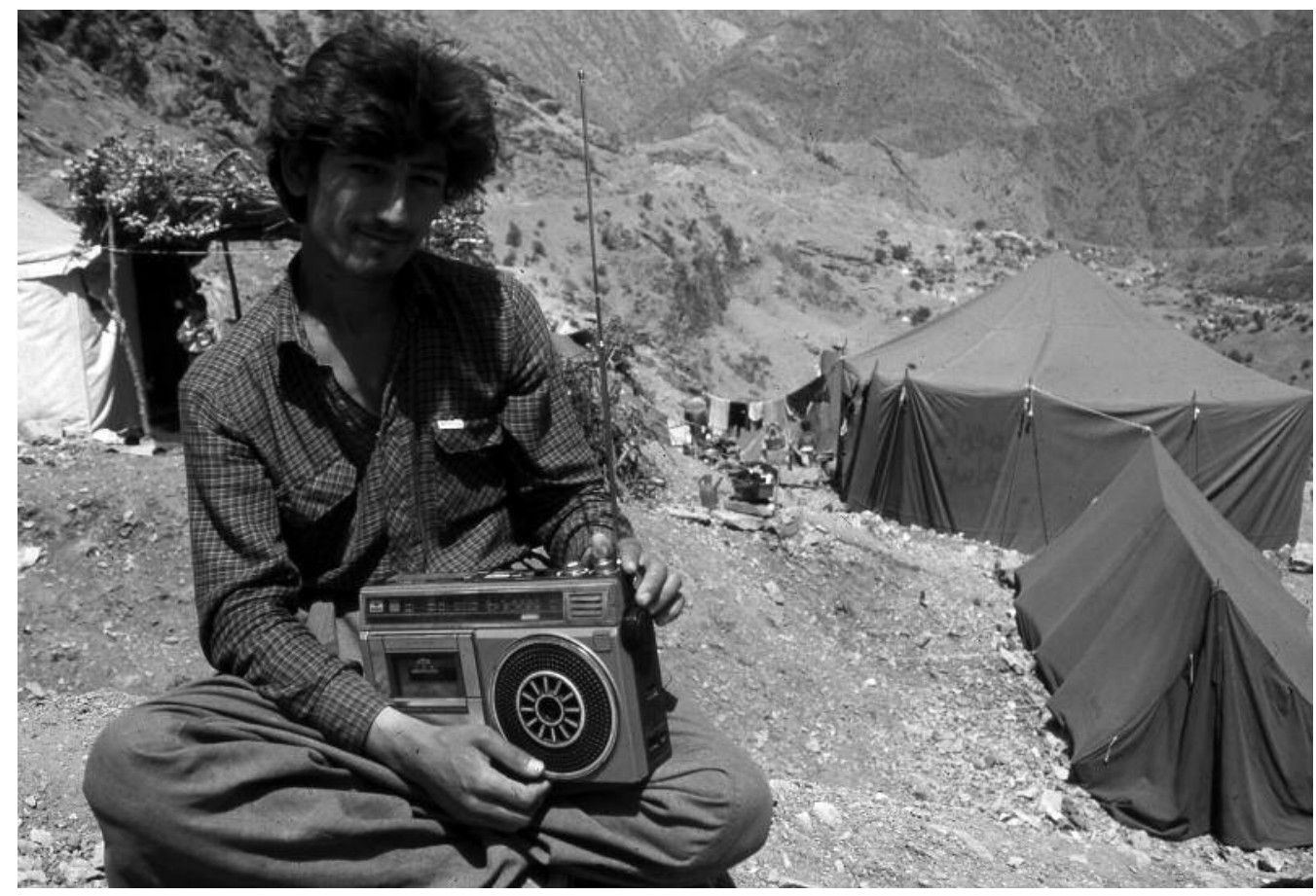

Nowsud, Kermanshah, Iran, juni 1991. En irakisk kurder i en flyktningleir i Iran følger med på nyhetene om forhandlinger mellom kurdiske ledere og Saddam Hussein. 


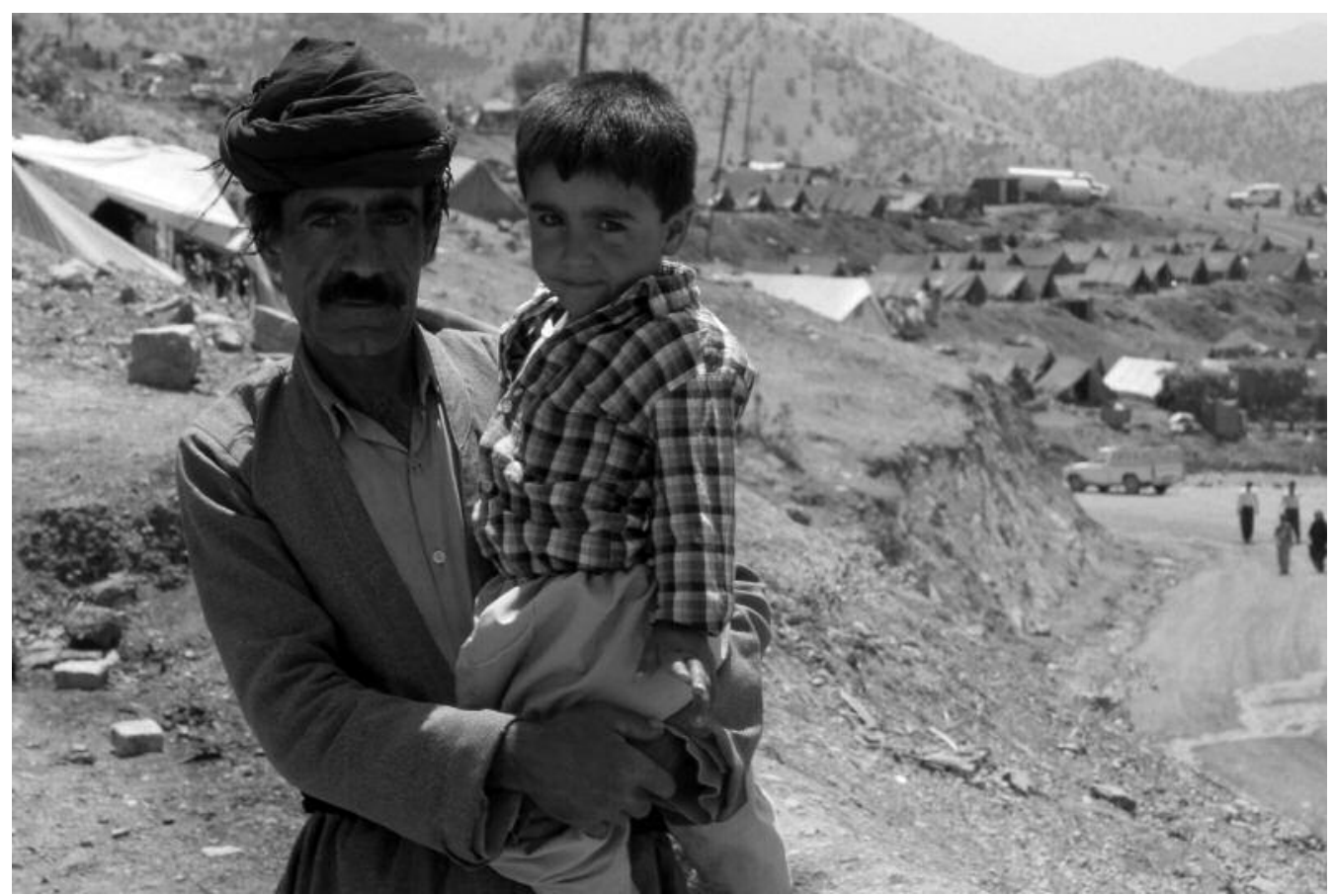

Nowsud, Kermanshah, Iran, juni 1991. Over en million irakiske kurdere flyktet over grensen til Iran under det kurdiske opprøret mot Saddam Hussein etter Gulfkrigen. 


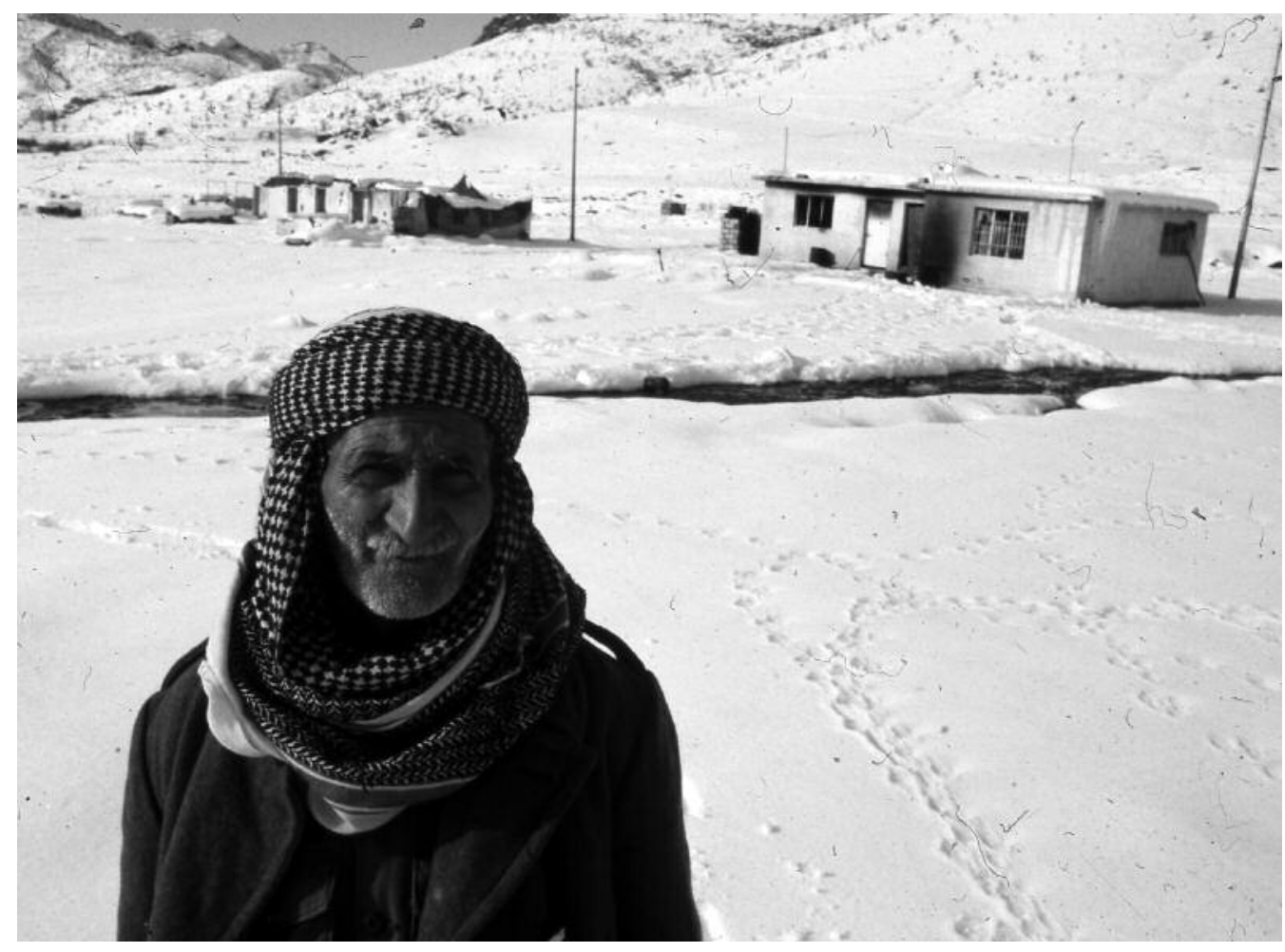

Landsbyen Banik, Nord-Irak, januar 1992. En irakiskkurdisk bonde har fått bombet husene sine av tyrkiske fly. 


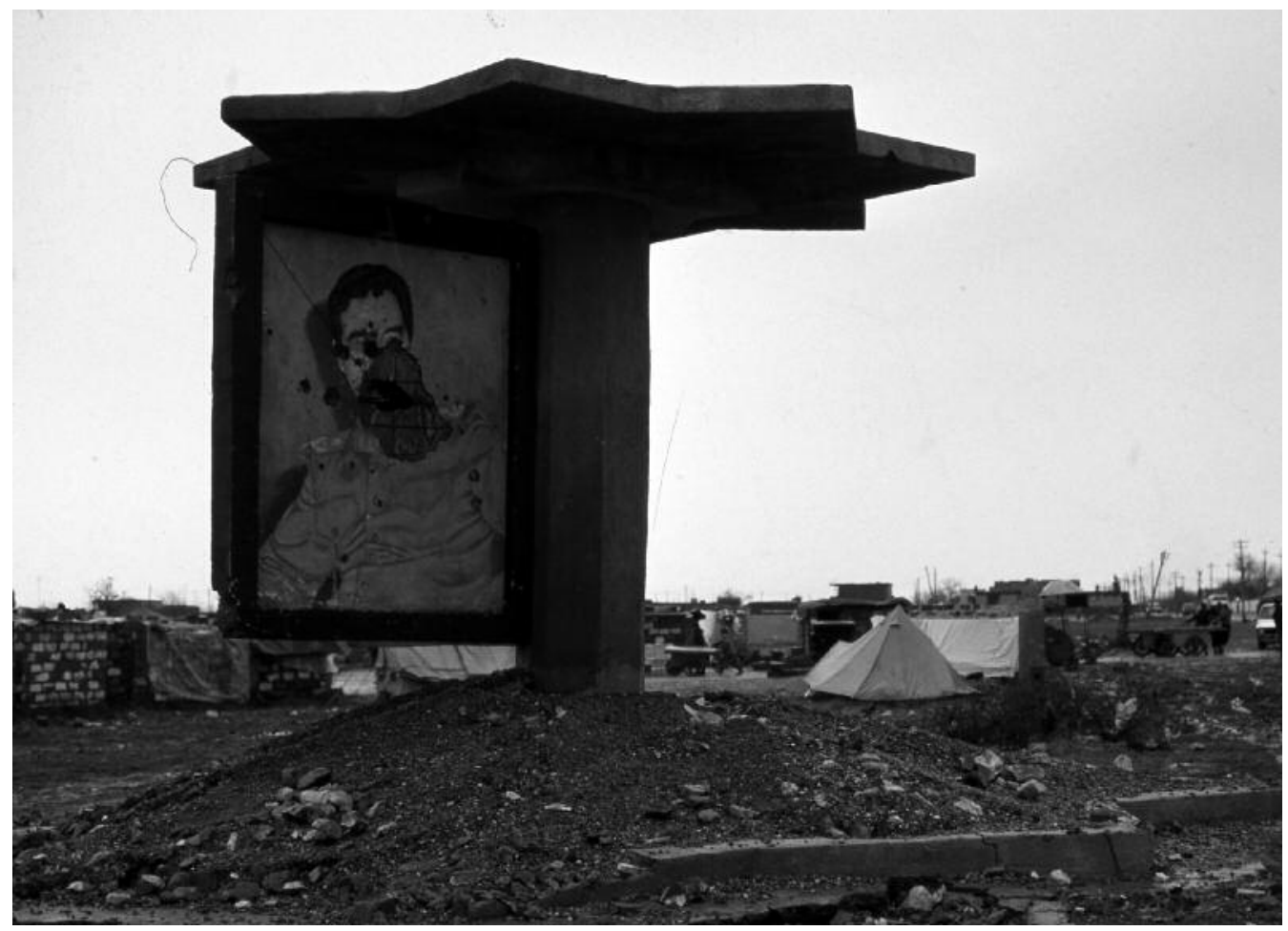

Halabja, Nord-Irak, januar 1992. Et portrett av Saddam Hussein er skutt i stykker av kurdisk peshmerga. 


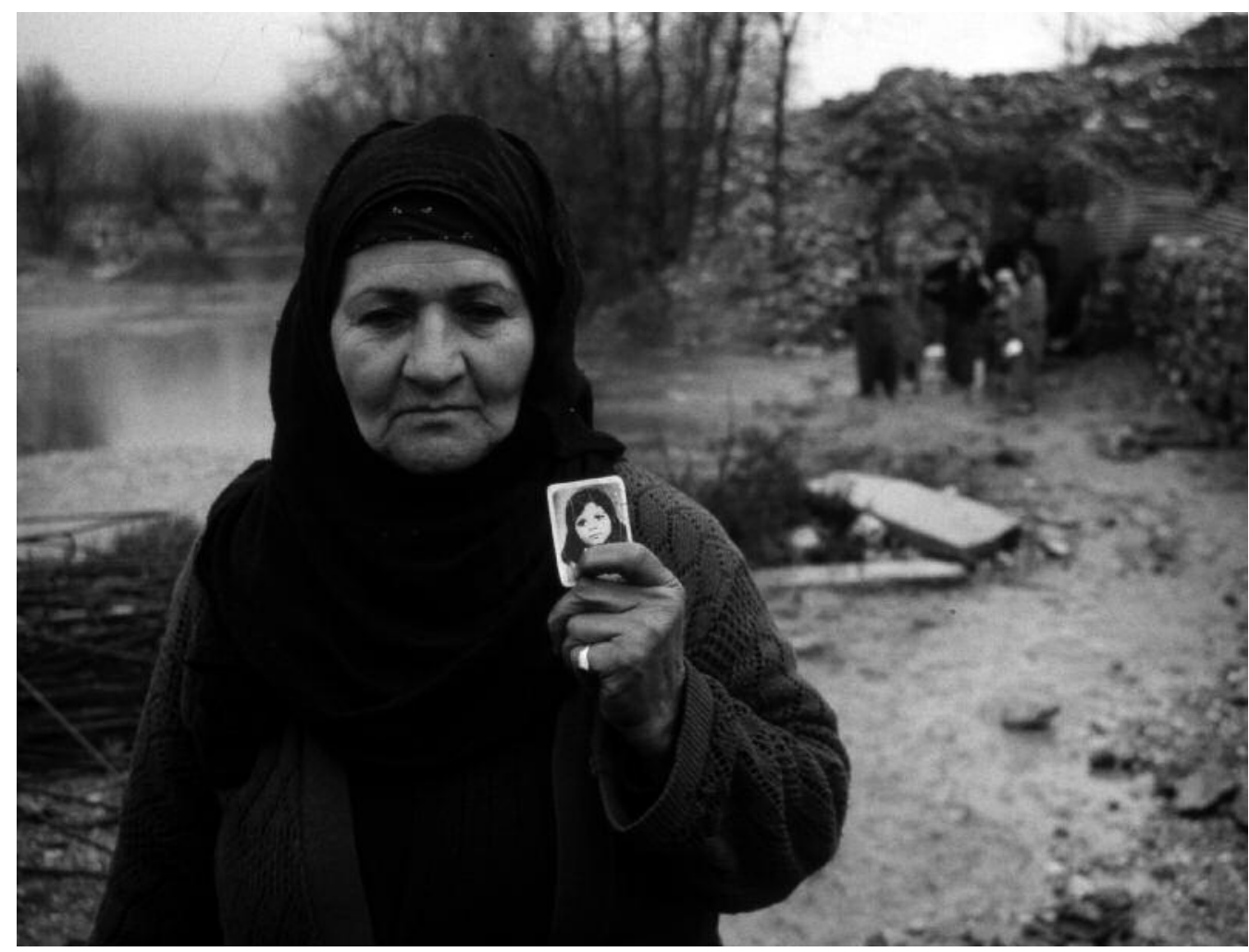

Landsby utenfor Halabja, Nord-Irak, januar 1992.

Kurdisk kvinne viser fram bilde av datteren som ble drept da irakiske styrker la landsbyen i grus. 


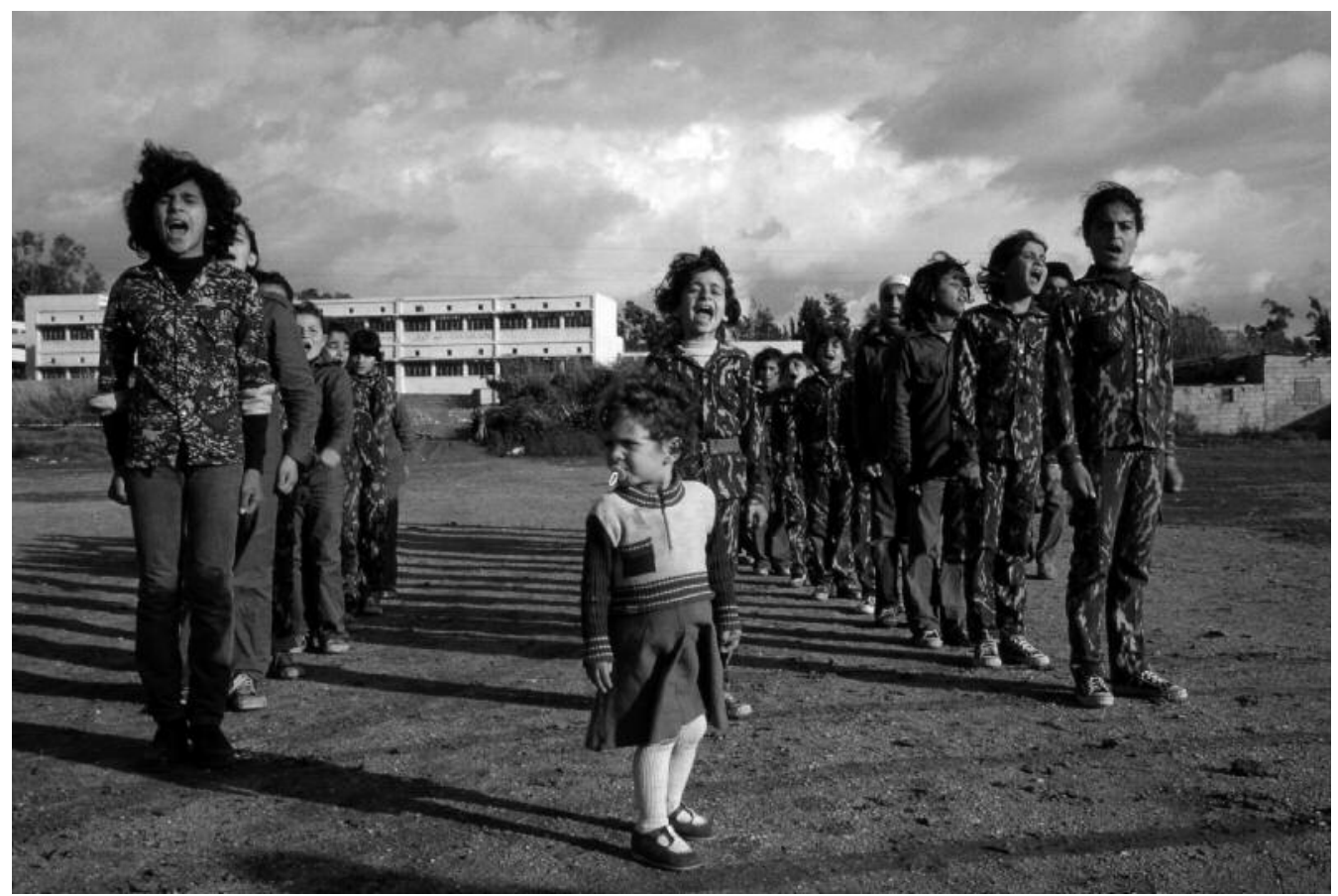

Den palestinske flyktningleiren Rashediyeh, desember

1981. En gruppe Ashbal - løveunger - roper et kamprop. 


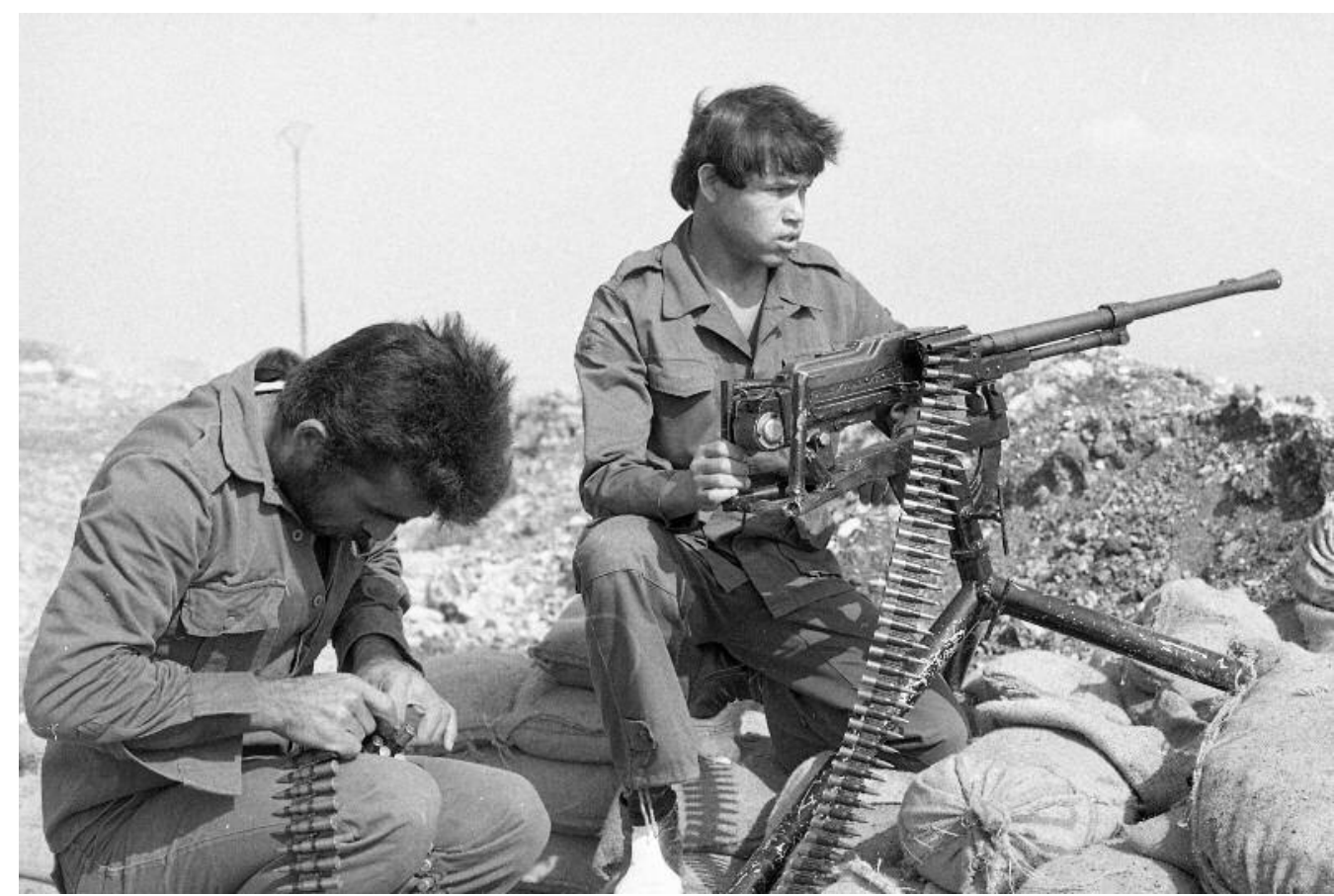

Fatah-posisjon på Terbol-fjellet utenfor flyktningleiren Baddawi, oktober 1983. 


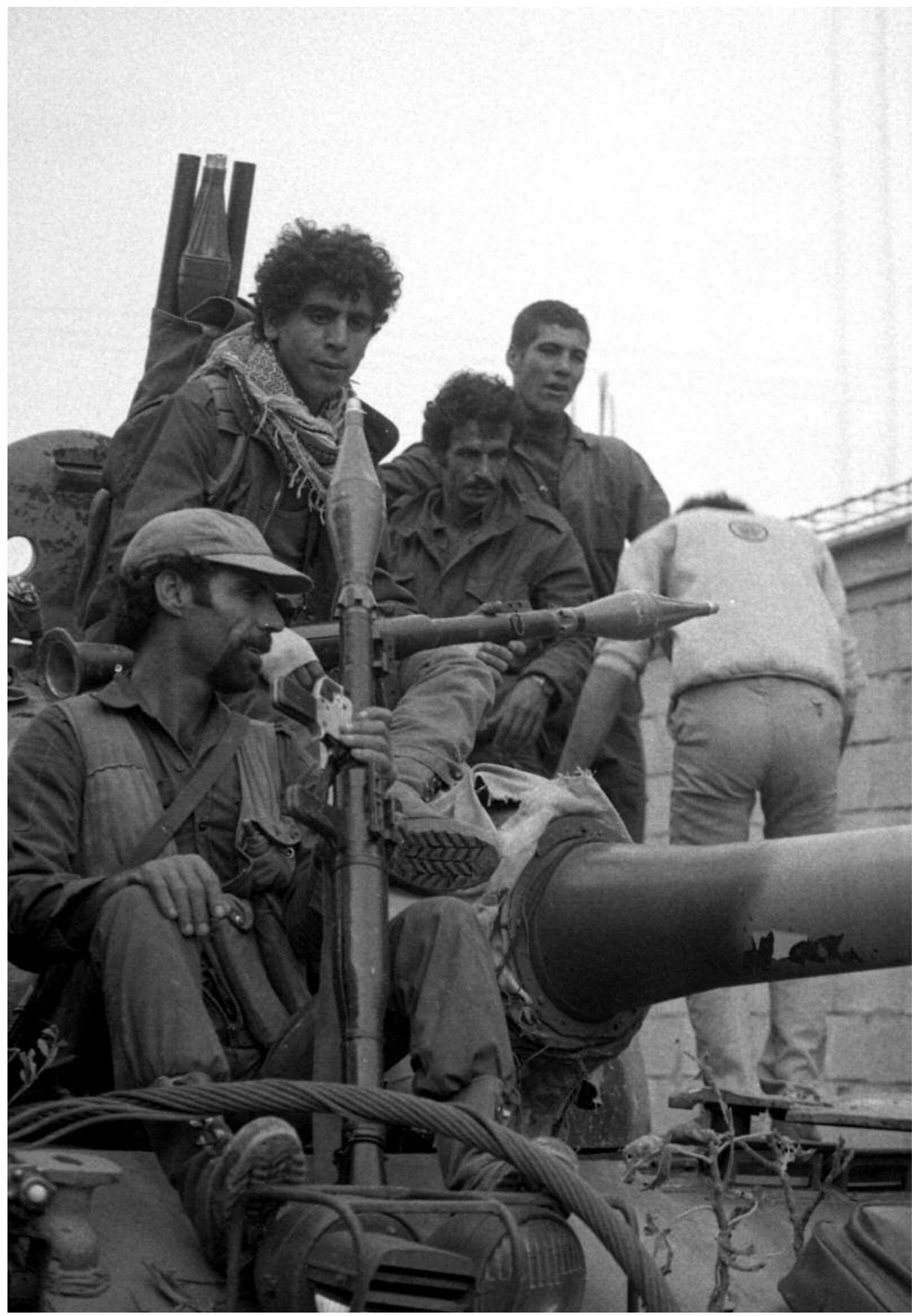




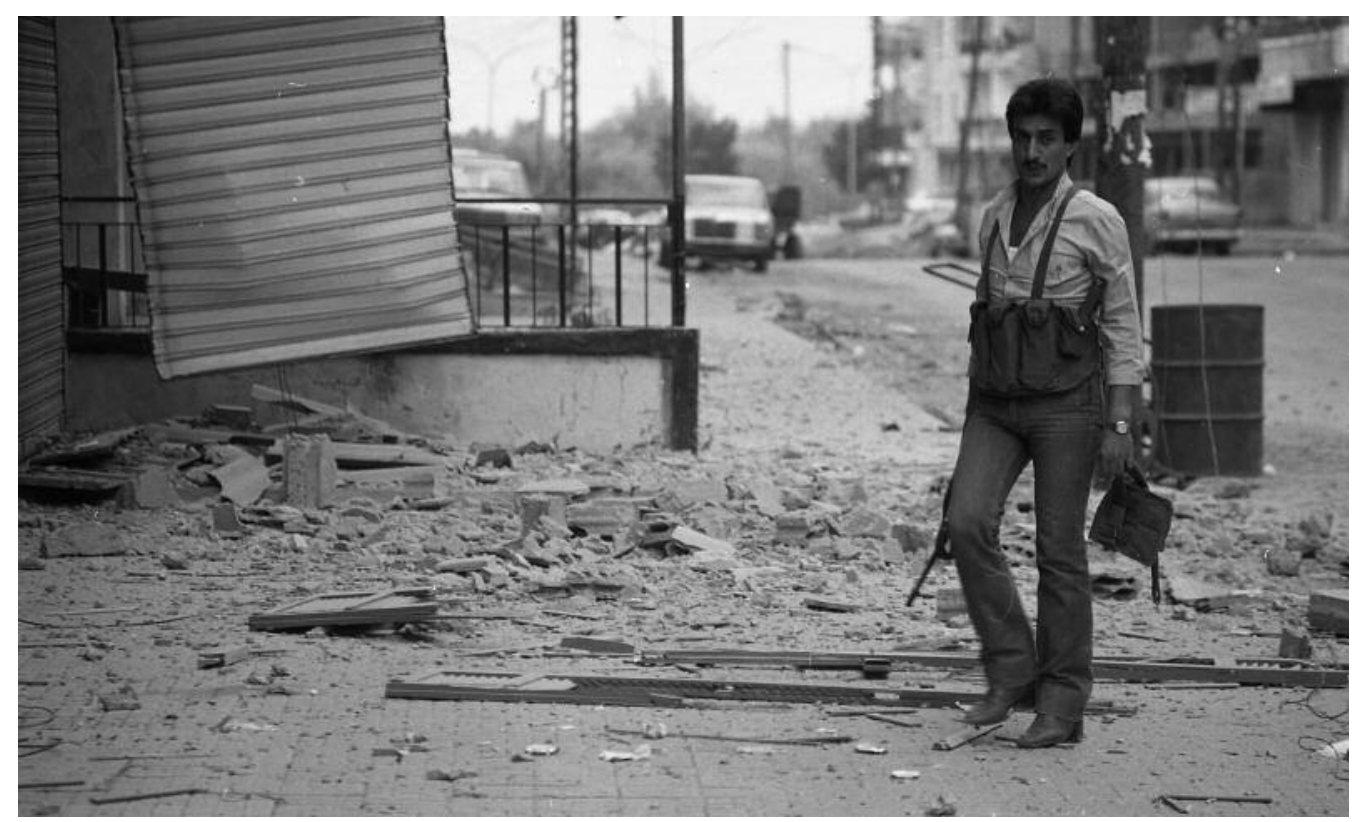

Over: Tripoli, Libanon, oktober 1983. Militssoldat i sentrum av Tripoli under krigen mellom Arafat-lojale Fatah-styrker og syrisk-støttede utbrytere fra Fatah.

Til venstre: Den palestinske flyktningleiren Baddawi utenfor Tripoli, Libanon, oktober 1983. Fatah-soldater har erobret en syrisk tanks fra Fatah-ubrytere som har omringet leiren. 


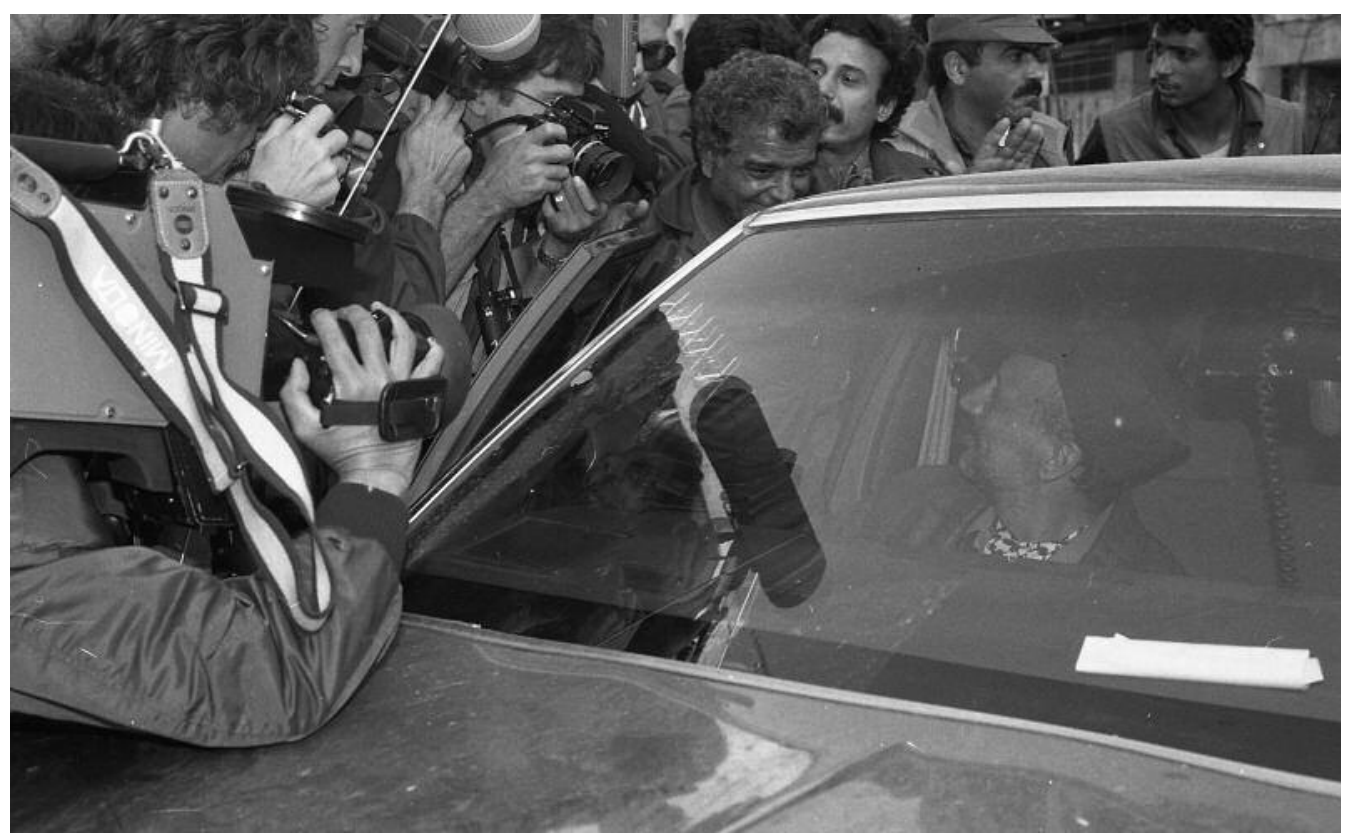

Tripoli, Libanon, oktober 1983. PLO-leder Yasser Arafats bil omringet av journalister under krigen mellom Arafat-lojale Fatah-styrker og syrisk-støttede utbrytere fra Fatah. 


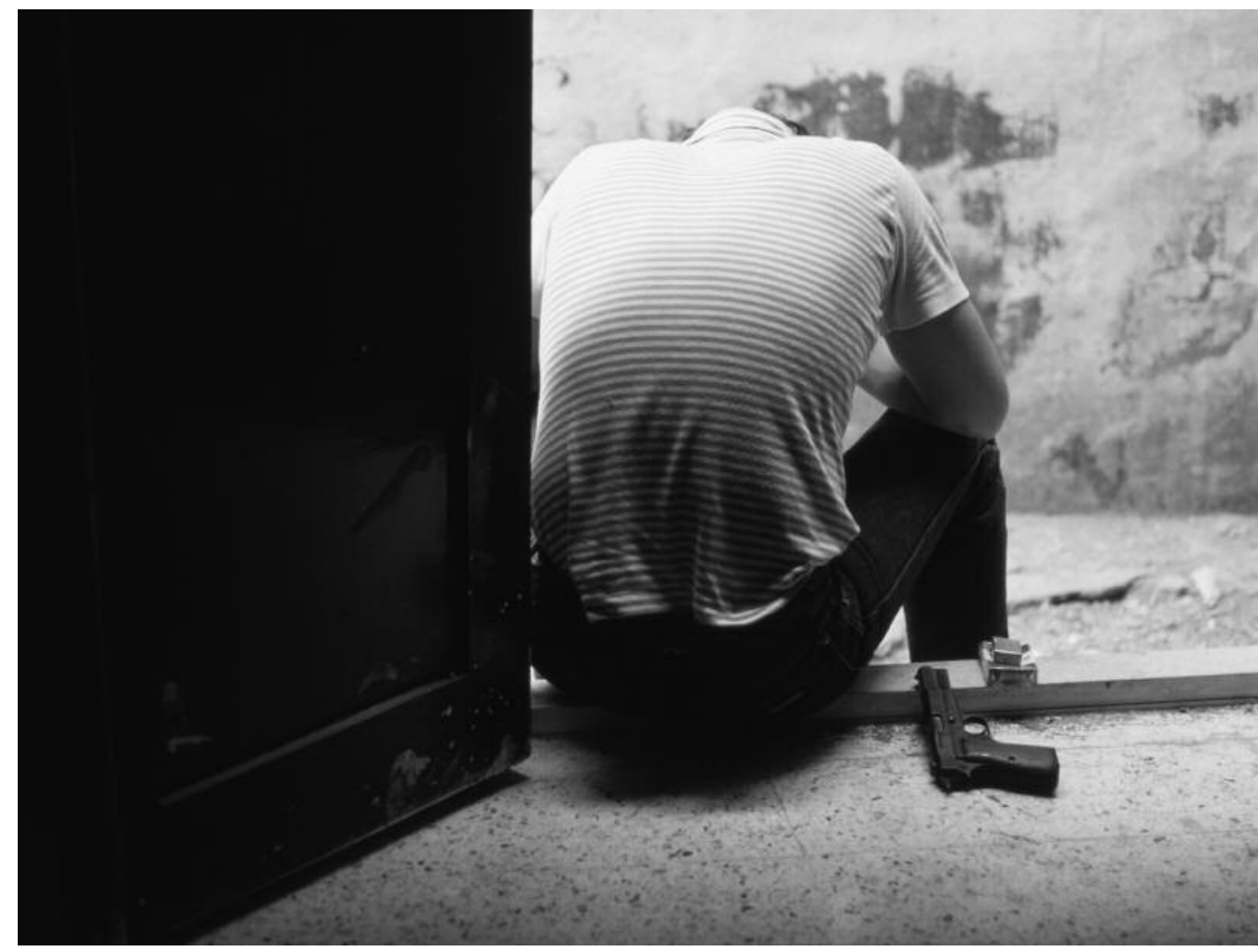

Den palestinske flyktningleiren Bourj el-Barajneh i Beirut, september 1985. Mann tar en røykepause under «leirkrigen» mellom palestinske styrker og den libanesiske Amal-militsens som har omringet leiren. 


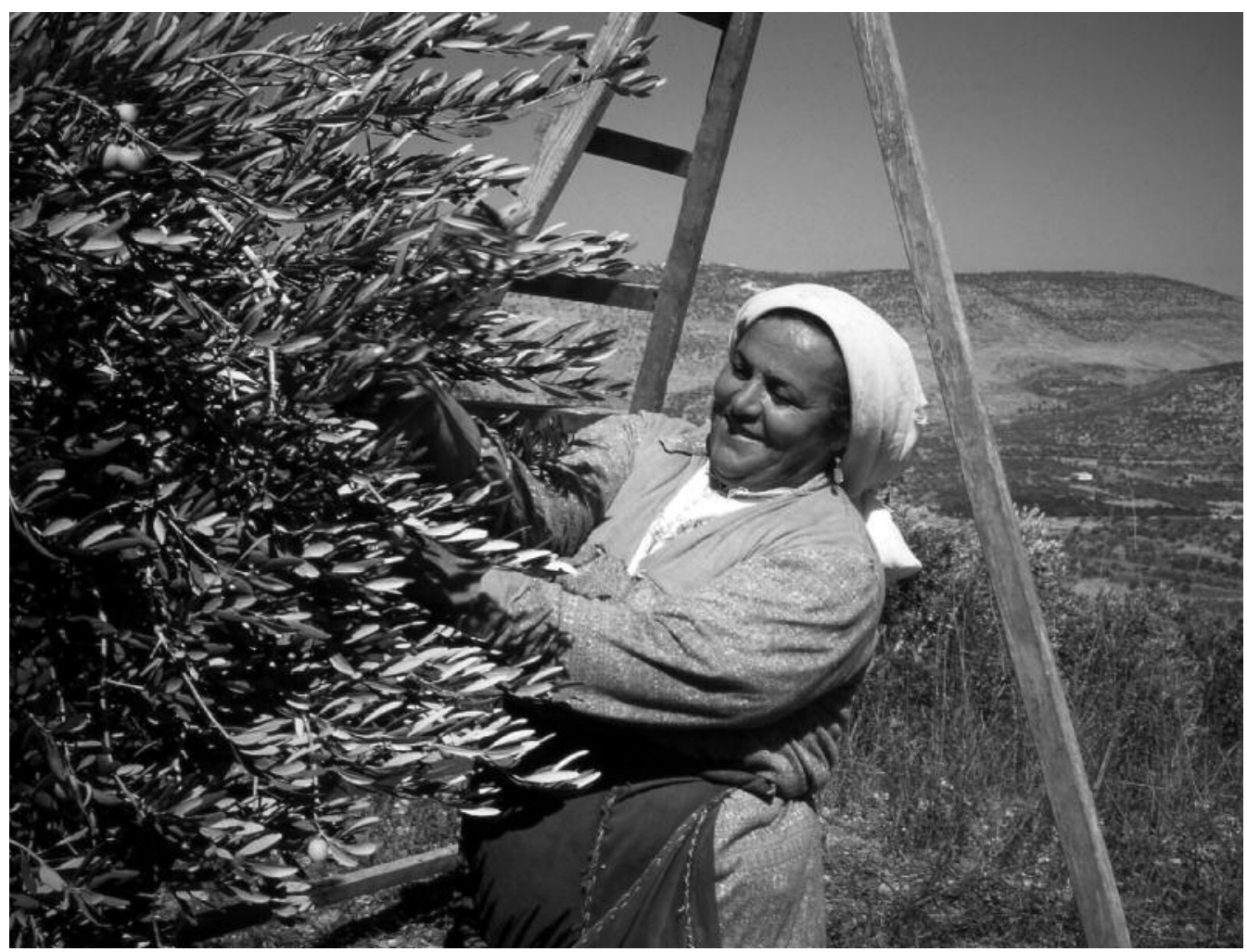

Annabta, Vestbredden, oktober 1995. Oliveninnhøsting i Palestina. 


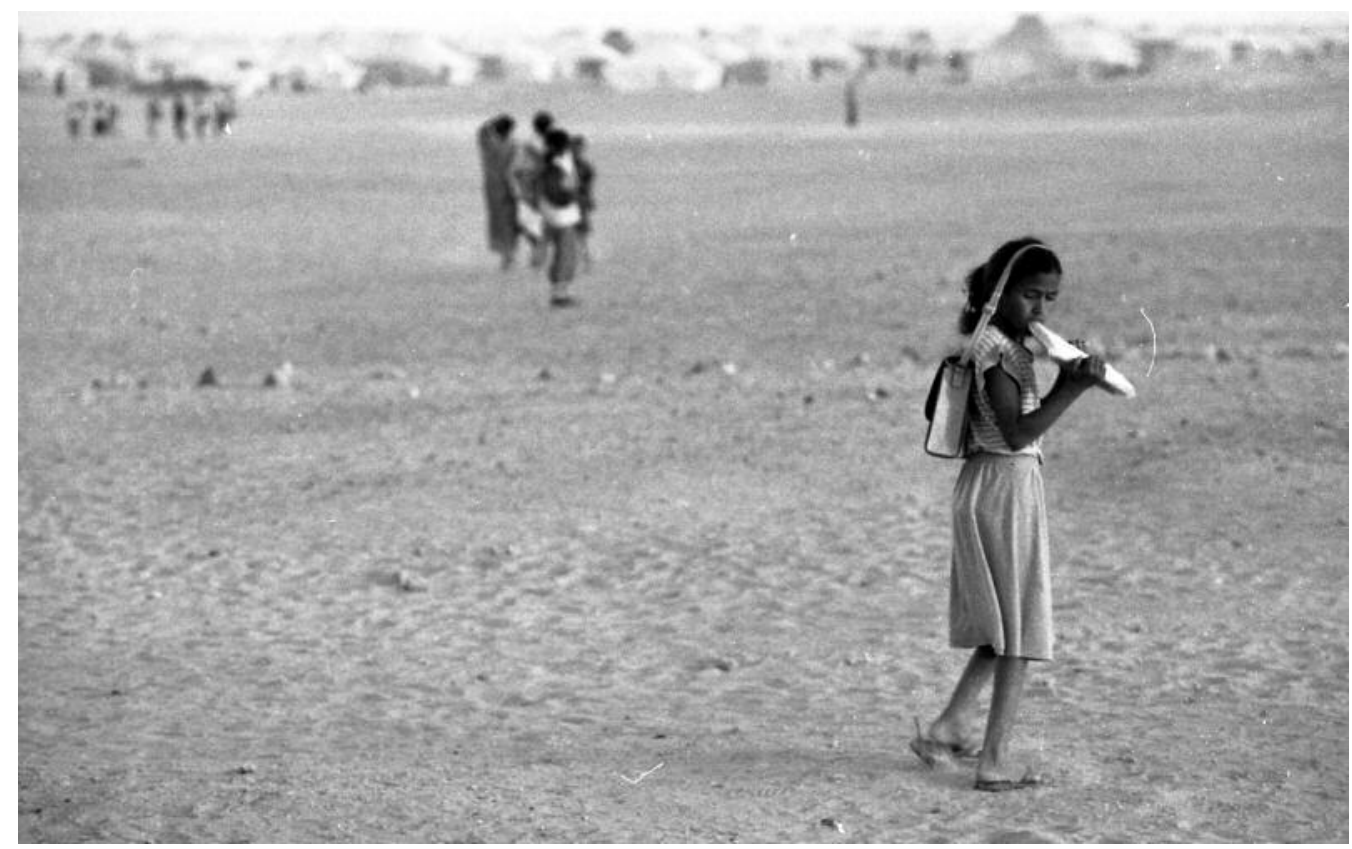

Sahrawi flyktningleir, Tindouf, Algerie, april 1986. Jente på vei hjem fra skolen. 


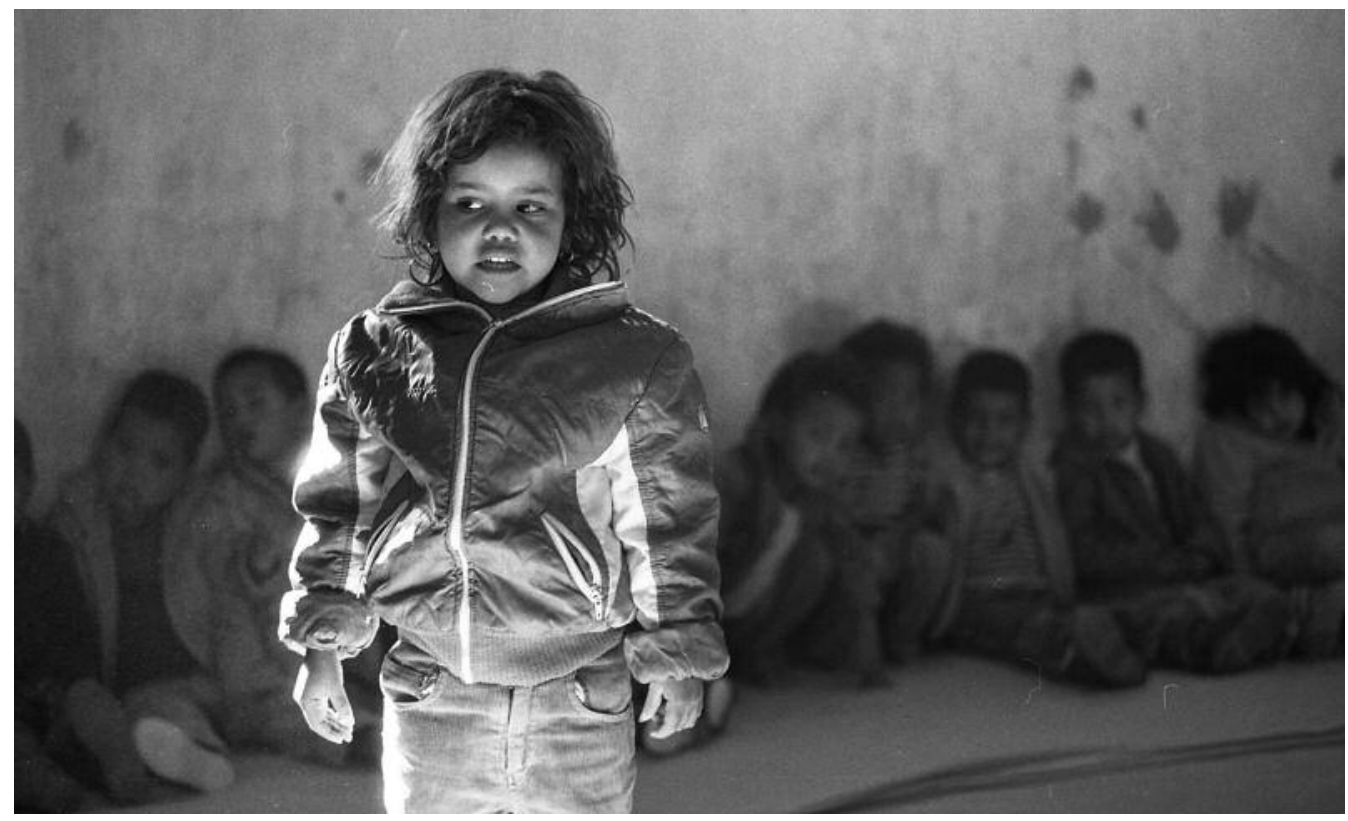

Sahrawi flyktningleir, Tindouf, Algerie, april 1986. Barnehage drevet av Polisario. 


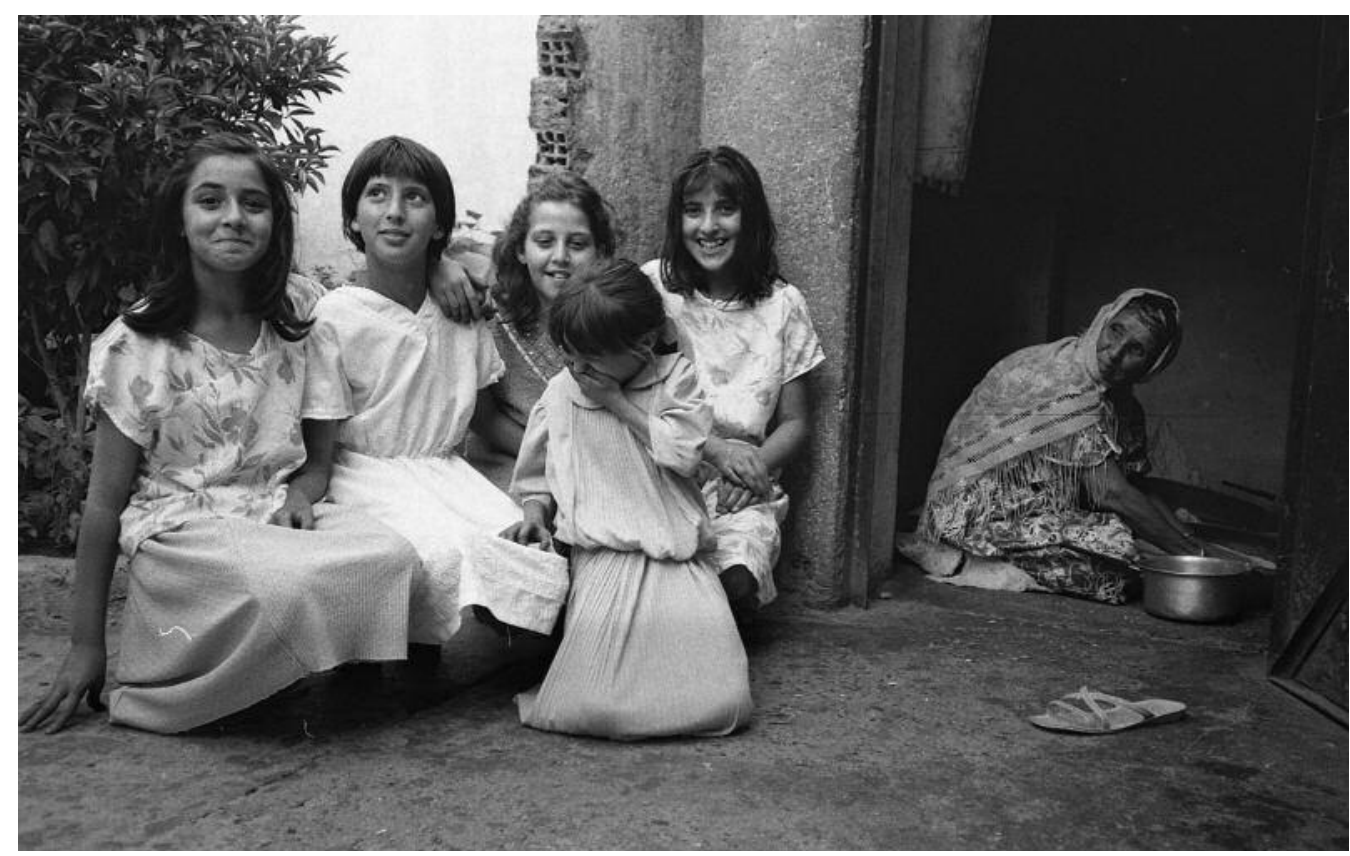

Kabylie, Algerie, juli 1989. Barna venter på middag mens bestemor lager berbernes nasjonalrett, couscous. 


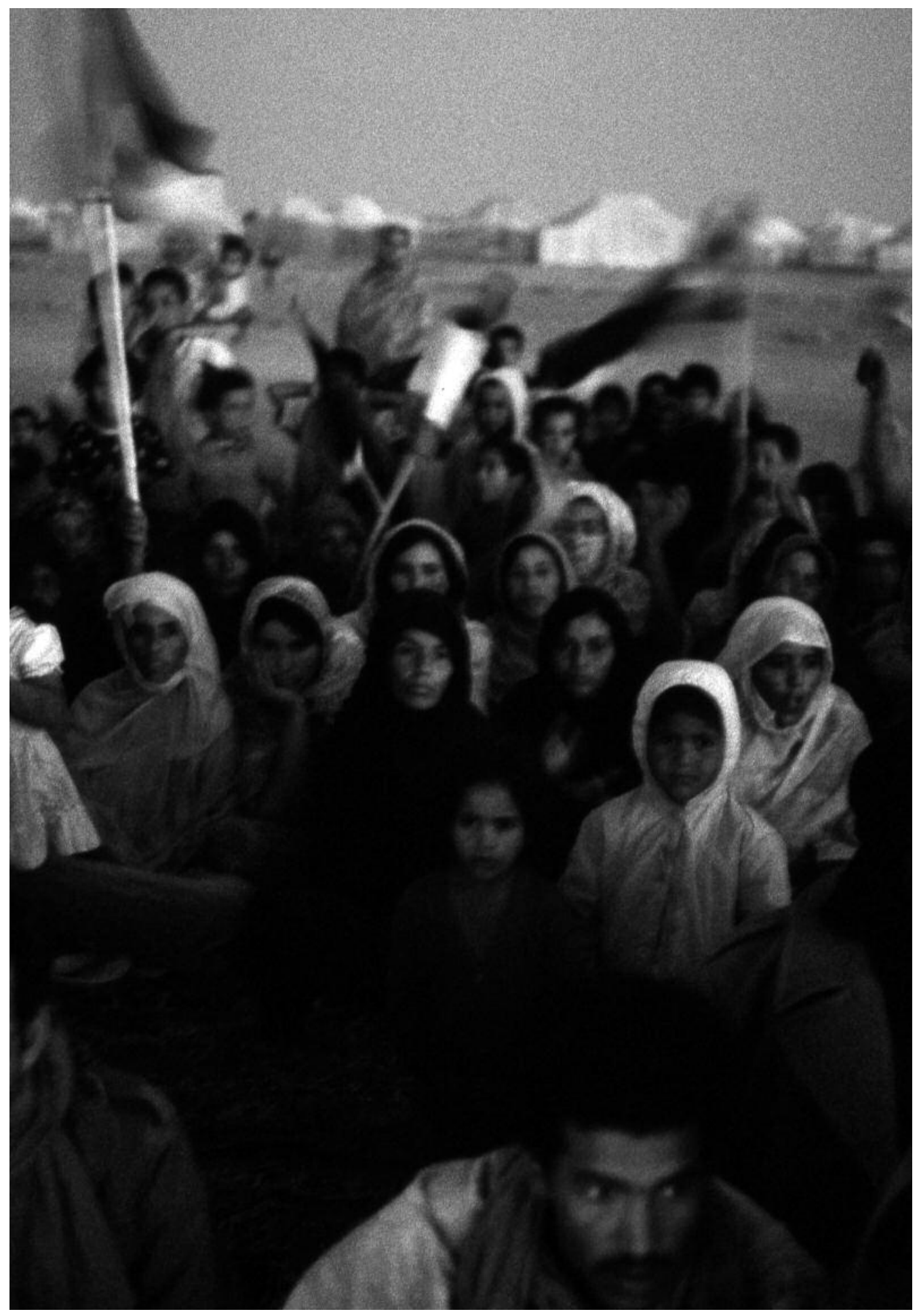




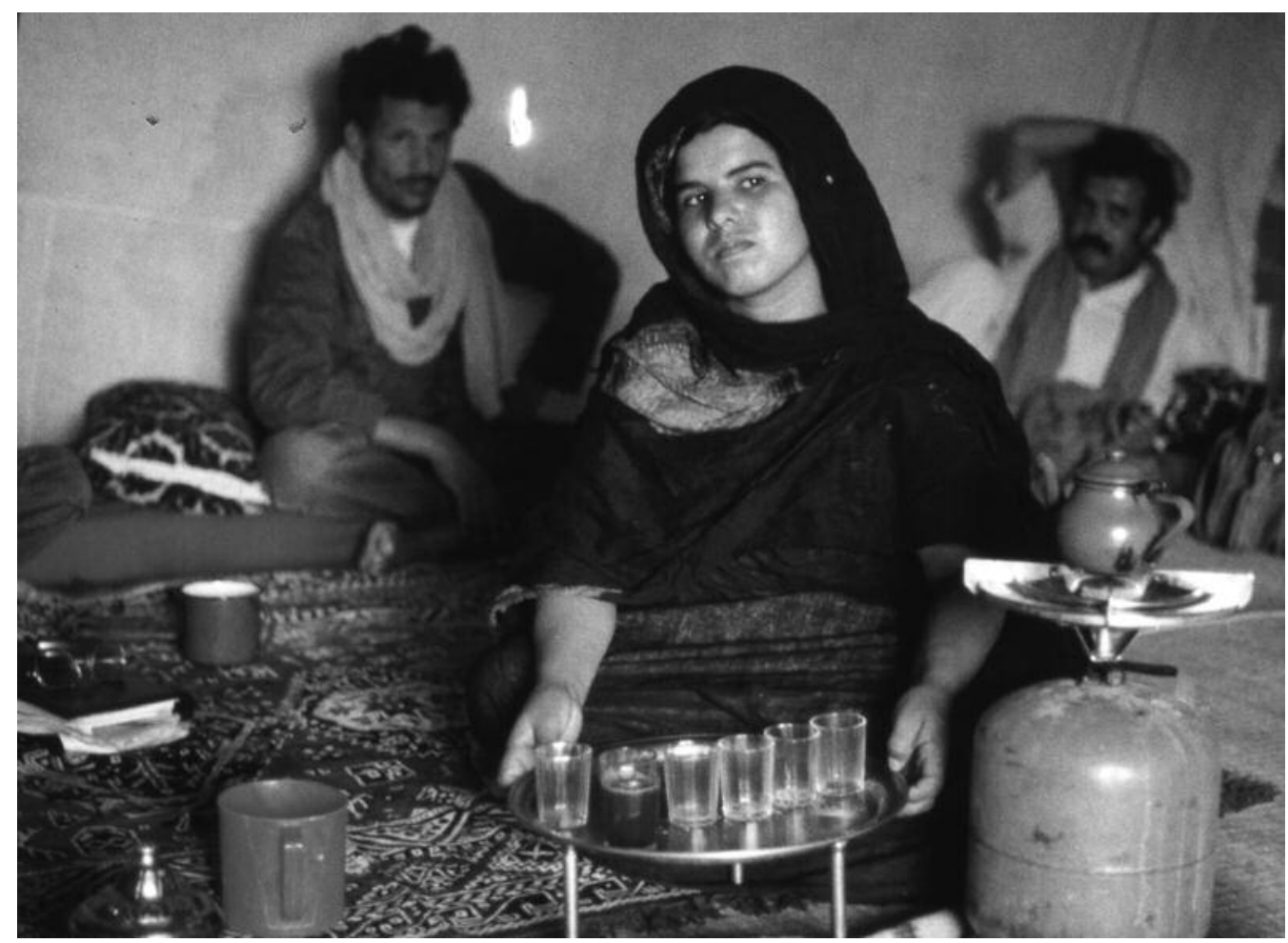

Over: Sahrawi flyktningleir, Tindouf, Algerie, april 1986.

Sahrawi-kvinne serverer te.

Til venstre: Sahrawi flyktningleir, Tindouf, Algerie, april 1986. Leirbeboerne samles om kvelden for sosialt samvær og nyheter fra Vest-Sahara. 